\title{
Analysis of investment appeal of the industrial enterprise by eigenstate method
}

\author{
O.S. Buslaeva ${ }^{1, *}, E . V$. Bunova $^{1}$, and C.N. Malovechko ${ }^{1}$ \\ ${ }^{1}$ South Ural State University, Chelyabinsk, Russia
}

\begin{abstract}
An analysis of enterprise performance is considered. The problem is solved based on the analysis of the base indicators of functioning of the enterprise in terms of improving economic stability, and also development of autoregulation mechanism of economical stability of enterprise. An eigenstate method is proposed for the analysis of the basic indicators of the enterprise as it allows to construct an economomical stability model of enterprise. Methodology of economic stability analysis of enterprise on the basis of eigenstate method is described. The formulas for calculating the complex indicator of economic stability are given. The effectiveness of the methodology is demonstrated on the example of economic stability analysis of the large trading company.
\end{abstract}

\section{Introduction}

The unstable situation in the world economy affected industrial plants the most severely. According to data presented in the article [1], the highest number of enterprises bankruptcies during the economic crisis takes place in the manufacturing industry and it is 35\% of all bankruptcy registrations. In that context, the priority development of the industrial enterprise is technical re-equipment of production, allowing the company to obtain competitive advantages and to proceed with a new high-tech and innovative products. Today, businesses that implement infrastructure investments show remarkable growth and have good prospects. To intensify the development of industrial enterprises requires new investments from the outside, i.e. various investments should be involved to upgrade the production, purchase equipment, reduce production costs, release new products, increase sales and labour productivity.

To attract investment company's management need to monitor the investment activity and analyze the investment attractiveness of the enterprise. Currently, the investment attractiveness of many Russian companies is at an insufficient level, as investors consider investment in the enterprise as a high-risk operation. This is due, firstly, to the underdevelopment of Russian stock market, restraining credit policy of banks in relation to enterprises, specific features and priorities of investment policy at the regional level. Secondly, the backwardness of company's management, as currently the management usually focuses mainly on short-term and narrow goal, rather than on the strategic objectives of the business development when it comes to investment attractiveness of the company to investors. In addition, the instability of the economic situation in the country and the geopolitical situation in the world affects the investment attractiveness of enterprises negatively. In this regard, adequate methods of analysis and investment attractiveness evaluation of enterprises is extremely important for investors since it makes it possible not only to minimize their risks, but also to get the greatest benefit from the investment of its assets in one or another company.

There is still no single definition of investment prospects of businesses in the world literature. However, all authors confirm the importance of this concept. For example, the following authors [2] state, «investment grade is important in economic terms because of the attractiveness of new corporate investment, generating new businesses, thus leading to complete economic development." Therefore, we can say that the investment attractiveness of the enterprise is not only the financial performance of its activities, but also a certain model that consists of qualitative and quantitative indicators characterizing the enterprise functioning in a certain environment. These indicators include assessment of external environment (political, legal, economic, social) and internal positioning of the enterprise in the external environment, the qualitative assessment of the financial and technological potential of the enterprise.

The urgency of an issue of the definition of industrial enterprises investment attractiveness and development of investment attractiveness evaluation and analysis mechanism has led to the certain fact. Today in the economic literature, along with the works of foreign authors, there is a sufficient number of domestic works devoted to the description of construction of methods of industrial enterprises investment attractiveness analysis [3-7]. All variety of

Corresponding author: buslaevaos@susu.ru 
methods can be divided into two groups. The first group includes methods that are based only on the results of the financial activities of the enterprise. The second group is methods that take into account both internal factors (financial performance) and external (legal, economic, social indicators that characterize the country, region or industry).

The first group of the investment attractiveness evaluation methods use only indicators of the enterprise economic activity. As a rule, there is an analysis of the company in the following areas:

1. Asset turnover analysis, taking into account the indicators: asset turnover ratio, current assets turnover ratio, turnover assets duration, current assets turnover duration.

2. Return on capital analysis, taking into account the indicators: the profitability of assets, profitability of current assets, key assets profitability, profitability of products realization, return on equity, profitability index).

3. Enterprise financial sustainability analysis, taking into account the indicators: equity to total assets ratio, financial leverage ratio, fixed indebtedness ratio.

4. Assets liquidity analysis, taking into account the indicators: absolute liquidity ratio, bank-liquidity ratio, debts receivable turnover period, receivable turnover ratio.

The technique described in the Beaver et al. [8] is relating to this group. Beaver et al. [8] find that the financial strength of the firm can be assessed by return on assets (EBIT to total assets), the ability of cash flow from operations pre-interest and pre-taxes to service the principal and interest payments, EBITDA to total liabilities, and leverage (total liabilities to total assets) allowing to predict up to five years prior to the critical event.

One of the methods described in [9] in the analysis of investment attractiveness is to assess the probability of bankruptcy or the company's solvency. Private investors, shareholders and banks are trying to reduce the risk of loss of their investment in the event of default.

In addition, it is offered to evaluate the investment attractiveness of companies using not only the internal measure of the enterprise activity, but also the environment indicators (the second group of methods). At the same time the concept of "investment climate" is introduced. Investment climate is defined in the article [3] as "a set of economic, political, social and other conditions that create a certain level of investments attractiveness." Only taking into account the original assessment of the investment climate investors can proceed to the evaluation of the investment attractiveness of a particular industrial enterprises.

Currently, dominant component analysis [10-13] and linear regression analysis [14-16] are widely used for the construction of models. However, typically dominant component analysis is limited by decrease of data dimension. Eigenstates method is a modification of the dominant component method, but in contrast to it, the main goal of eigenstates method is to build a reference model. To construct the reference model it is necessary to formulate criteria for the enterprise operation as an ideal social and economic system from a perspective of investment attractiveness. These requirements may limit the change in some (basic) indicators of its activity. The reference activity is an activity in which the change is fully consistent with the stated requirements. Application of the eigenstates method allows to show the functional condition of the company at any time as a weighted combination of eigenstates. Each eigenstate is a single-factor model, characterizing a certain process or tendency in the functioning of the industrial enterprise. Under this model, indicators of industrial enterprises activity vary in proportion to the weights of eigenstates and their values depend on a single factor.

This article describes a method of constructing the model of investment attractiveness analysis for the industrial enterprise on the basis of a method of eigenstates. The developed method is a tool for effective analysis of an enterprise operating rates. It also helps to control enterprise assets, as well as manage its costs successfully.

\section{The procedure of constructing the model of evaluation and investment attractiveness analysis}

To build the model of the investment-attractive industrial enterprises functioning we need to examine a methodology that allows to identify the structure of relationships and to build a generalized indicator of the company investment attractiveness along with reducing the number of analyzed basic indicators of the enterprise economic activity.

The construction of the investment model of the object can be divided into five stages.

The first stage is the formation of an indicators set describing the company's investment attractiveness. For in-depth study of investment attractiveness of industrial enterprises selected indicators should describe not only financial processes but also industrial or ecological ones. All figures should be normalized. Normalization involves error elimination, missing data, and the alignment of indicators change ranges (ie parameters should be changed in one range of numbers, for example from 0 to 1000).

In the second stage the requirements for the industrial enterprises investment attractiveness, which are either a restriction on a change of certain indicators or a set of investment attractiveness indicators with statutory meaning, are formulated. Most often asset turnover analysis, return on capital analysis and assets liquidity analysis are included in the investment attractiveness indicators analysis.

For example, analyzing the investment attractiveness of the region we can say that an increase in investment into the region entails an increase in the gross regional product. The constructed model is an idealized representation of an object behavior.

The third stage involves the calculation of eigenstates of the industrial enterprise. In order to 
determine the weighting factors of eigenstates it is necessary to solve the problems of eigenvalue matrix. The covariance matrix or the initial second moments matrix can be used as eigenvalue matrix. Each eigenvector has the same dimension as the economic system state vector, and the eigenvector coefficients are interpreted as the weights of eigenstates indicators. Thus, each eigenvector describes enterprise eigenstate, which characterizes a certain tendency of enterprise functioning and development. If to calculate the eigenstates coefficient we use covariance matrix, the vector of mean values is the main component of the investment attractive company model. In addition, if the means do not satisfy the requirements of the enterprise for investments attraction, the model cannot be built. Therefore, to calculate the weight of eigenstates we offer to use the coefficients of the initial second moments matrix. All distinguished eigenstates are independent (the first property of eigenstates [17, 18 , ie the development of a trend (eigenstate) does not affect the development of other trends (eigenstates). Thus, the removal of certain eigenstates does not change others eigenstates. Within each trend (eigenstate) values vary in proportion to the weights of eigenstates (the second property of eigenstates [17, 18].

In the fourth stage, the construction of the investment attractiveness model (reference model) of eigenstates obtained in the previous step. The main requirement for the model is that the activities described by the reference model, must comply with the requirements of enterprise investment attractiveness. If the requirements are presented in the form of restrictions on a certain indicators changing, we check the match between initial index modifications of reference activities to the requirements of the enterprise investment attractiveness using the second property of eigenstates. The process of building the reference model is the search of such eigenstates, which combination describes the activities satisfying the requirements of the investment attractiveness of the enterprise. If requirements of the enterprise investment attractiveness are rather strict restriction to the indices changes, there may be no eigenstates combination to describe the indices changes that satisfy these requirements. The number of possible combinations can be substantially reduced by using only eigenstates, which correspond to the requirements of the enterprise investment attractiveness.

If the investment attractiveness requirements are presented in the form of restrictions to indicators change, then according to the second property of eigenstates, base values in eigenstate vary in proportion to weights of eigenstates. It allows to assess the conformity of eigenstates of the enterprise investment attractiveness requirements.

If the investment attractiveness requirements are presented in the form of investment attractiveness indicators and their normative values, values indicators are calculated for each eigenstate. Let the stability indicator is the ratio of $x_{i}$ and $x_{j}$. As part of $h^{\text {th }}$ eigenstate, these parameters values are determined by the equation:

$$
x_{k i}^{h}=V_{h i} z_{k h} \quad x_{k j}^{h}=V_{h j} z_{k h}
$$

where $V_{h i}$ - the ratio of $h^{\text {th }}$ eigenstate of $i^{\text {th }}$ index, $z_{k h}-$ the main component of $\mathrm{h}^{\text {th }}$ eigenstate for $\mathrm{k}^{\text {th }}$ observation.

Selected eigenstates are used to generate the enterprise investment attractiveness model (the reference model). The resulting model is an idealization of real activity and serves as a standard for the investigated companies in terms of investment attractiveness.

We differ models with a constant and a variable number of eigenstates. The model with a fixed number of eigenstates uses the same number of eigenstates to calculate indicators:

$$
x_{k i}^{e t}=\sum_{f=1}^{p} V_{h i} z_{k h}
$$

where $h=l(f), l(\ldots)-$ a list of eigenstates numbers, $p-$ the number of eigenstates used to build the model.

The model with a variable number of eigenstates changes the number of eigenstates, depending on the principal components sign. In this case there are three groups of eigenstates: 1) the group of permanent eigenstates; 2) a group of eigenstates with positive main components; 3) a group of eigenstates with negative main components. The eigenstates of the first group are always used, the eigenstates of the second group are used only if the corresponding principal components are positive, and finally, the eigenstates of the third group are used only if the principal components are negative:

$$
\begin{aligned}
& x_{k i}^{e t}=\sum_{f=1}^{p_{1}} V_{h_{1} i} z_{k h_{2}}+\sum_{f=1}^{p_{2}}\left\{\begin{array}{c}
V_{h_{2} i} z_{k h_{2}}, \text { if } z_{k h_{2}} \geq 0 \\
0 \quad \text {, if } z_{k h_{2}} \leq 0
\end{array}+\right. \\
& +\sum_{f}^{p_{3}}\left\{\begin{array}{c}
V_{h_{3} i} z_{k h_{3}} \text {, if } z_{k h_{3}} \leq 0 \\
0 \quad \text {,if } z_{k h_{3}} \geq 0
\end{array}\right.
\end{aligned}
$$

Here, $h_{1}=l_{1}(f), h_{2}=l_{2}(f), h_{3}=l_{3}(f)$ where $l_{1}(\ldots)$, $l_{2}(\ldots), l_{3}(\ldots)$, are lists of eigenstates of the first, second and third groups, $p_{1}, p_{2}, p_{3}$ - the number of the principal components of the first, second and third groups.

At the last stage, analysis of investment attractiveness of the object is carried out. This analysis is done by comparing the actual and reference values of the enterprise performance by using the penalty function method.

Comparing actual performance with reference shows how the actual state of the enterprise corresponds to the reference one. The reference values are calculated on the basis of the standard model of investment attractiveness. Large deviations (eg, deviations of more than $10 \%$ ) from the reference values can be interpreted as an attendant instabilities object development, and as a consequence, a decrease in its investment attractiveness. Thus, the main objective of the object investment attractiveness management in our 
view lies in the analysis of the main indicators of the socio-economic object activity, in the early detection of abnormalities that may lead to the destabilization of the development and detection of possible risks of investment loss.

Thus, the main objective of effective enterprise management is the timely detection of deviations, destabilizing activities, identification of possible threats, exploration of the sources and their causes, their solutions in order to maintain the investment attractiveness of the enterprise.

Comprehensive investment potential indicator can be obtained by the equation:

$$
I_{y}=1-\bar{f}_{k}
$$

where $\bar{f}_{k j}-$ the mean square root of the penalty function indicators, which is defined by the equation:

$$
\overline{f_{k}}=\sqrt{\frac{1}{r} \sum_{j=1}^{r} f_{k j}^{2}}
$$

Here, $f_{k j}$ represents the penalty function value for the $j$-th index of $k^{\text {th }}$ observation, $r-$ the number of indicators used for the construction of an integrated indicator of investment attractiveness.

\section{Industrial enterprise investment attractiveness research}

As an example we consider the investment attractiveness of the enterprises of metallurgical industry. To select the parameters that characterize the investment attractiveness of the enterprise it is reasonable to use its financial statements for the 5 years from 2010 to 2014 (external factors are not taken into account, since the investment attractiveness of the country, the region and the industry are considered to be positive). The main indicators of the enterprise economic activity three groups of indicators are taken:

1. Indicators of the company main activities (production factors): revenue, prime cost, finished output volume, profit. 2. The Company's assets: fixed assets, stores, investments, etc.

3. Company Liabilities: undistributed profits, debt, current engagements, borrowed funds.

To build models we accept the criteria specific to the classical methods of enterprises investment attractiveness evaluation. We believe that the investor is willing to invest their capital with minimal risk to the company if: net profit margin is greater than 0.3 ; current assets turnover is more than 0.25 ; the ratio of receivables and payables is greater than 1; the ratio of debt capital and the company's assets and return on assets is greater than 0.1 ; working capital ratio is more than two.

Based on of the second moment's matrix calculation, eigenstates for the selected factors are counted. Fragment of the eigenstates weight numbers calculating are presented in "Tab. 1".

Penalty functions values depend on the principle of comparison of reference and actual values of the enterprise performance. It is proposed to use a cost and result-based method, under which the penalty function value depends on the types of indicators (cost and result).

If the value of the cost index exceeds the reference and is below value of this index at a predetermined level, then the excess is considered a sign of inefficiency and measured by the penalty function.

In order to choose eigenstates that meet the criteria laid down it is necessary to calculate the required indicators for each of eigenstates (fragment calculations are presented in Table 2 .

Analysis of eigenstates showed that only one eigenstate is suited to the requirements.

Table 1. Eigenstates weight numbers.

\begin{tabular}{|c|c|c|c|c|c|c|}
\hline Eigenstates (bln. rub.) & indicator name & $\mathbf{1}$ & $\mathbf{2}$ & $\mathbf{3}$ & $\mathbf{4}$ & $\mathbf{5}$ \\
\hline fixed assets & $\mathrm{X} 1$ & 0.096 & 0.202 & 0.290 & 0.758 & 0.018 \\
\hline stores & $\mathrm{X} 2$ & 0.044 & 0.127 & -0.215 & -0.141 & -0.116 \\
\hline accounts receivable & $\mathrm{X} 3$ & 0.108 & 0.050 & -0.029 & -0.019 & 0.026 \\
\hline investments & $\mathrm{X} 4$ & 0.275 & -0.446 & 0.223 & -0.321 & 0.451 \\
\hline Working assets & $\mathrm{X} 5$ & 5.062 & 5.043 & 15.140 & 14.169 & 16.878 \\
\hline owned capital & $\mathrm{X} 6$ & 0.467 & -0.185 & 0.035 & 0.177 & -0.105 \\
\hline long-term liabilities & $\mathrm{X} 7$ & 0.004 & 0.003 & -0.025 & 0.065 & 0.003 \\
\hline borrowing costs & $\mathrm{X} 8$ & 0.072 & 0.122 & -0.125 & 0.058 & -0.047 \\
\hline credit indebtedness,. & $\mathrm{X} 9$ & 0.046 & -0.057 & -0.024 & -0.233 & -0.240 \\
\hline short-term debt, bln. rub. & $\mathrm{X} 10$ & 0.124 & 0.095 & -0.223 & 0.036 & -0.342 \\
\hline revenue & $\mathrm{X} 11$ & 0.328 & 0.398 & -0.010 & -0.176 & -0.096 \\
\hline before-tax profit (loss) & $\mathrm{X} 12$ & 0.130 & 0.356 & 0.129 & -0.123 & 0.193 \\
\hline net income & $\mathrm{X} 13$ & 0.104 & 0.287 & 0.103 & -0.118 & 0.158 \\
\hline net assets & $\mathrm{X} 14$ & 0.466 & -0.191 & 0.052 & 0.128 & -0.088 \\
\hline finished output & $\mathrm{X}_{15}$ & 0.002 & 0.001 & 0.010 & 0.001 & -0.016 \\
\hline
\end{tabular}


Table 2. Indicators of eigenstates investment attractiveness.

\begin{tabular}{|c|c|c|c|c|c|}
\hline Eigenstates number & $\mathbf{1}$ & $\mathbf{2}$ & $\mathbf{3}$ & $\mathbf{4}$ & $\mathbf{5}$ \\
\hline net margin & 0.31 & 0.72 & -10.32 & 0.67 & -1.65 \\
\hline working capital turnover & 0.744 & -2.139 & 0.057 & -1.497 & -0.914 \\
\hline working capital ratio & 3.557 & -1.947 & 0.787 & 3.276 & -0.306 \\
\hline short-term debt and debt receivable ratio & 1.141 & 1.897 & 7.7633 & -1.867 & -13.3 \\
\hline the ratio of receivables and payables & 2.349 & -0.885 & 1.188 & 0.082 & -0.106 \\
\hline proportion of credit debt in borrowed capital & 0.362 & -0.576 & 0.097 & -2.315 & 0.709 \\
\hline leverage & 0.240 & -0.665 & 0.266 & 0.485 & -0.882 \\
\hline return on assets & 0.196 & -1.936 & -0.110 & -0.570 & 0.412 \\
\hline
\end{tabular}

On the first of eigenstate we build a reference model of the investment attractiveness of the company. The dependence of the reference and the actual indicators of economic and financial activity of the enterprise are shown in "Fig. 1-2".

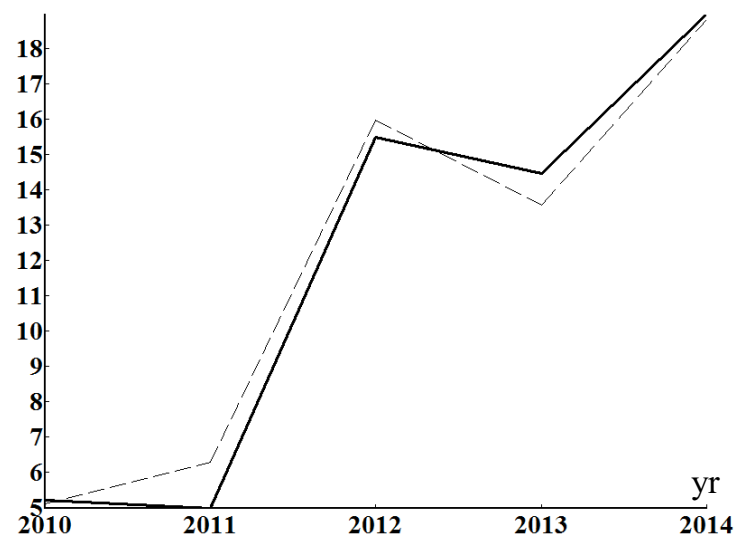

Fig. 1. Owned capital (hereinafter solid line is a model, dashed line is the original values).

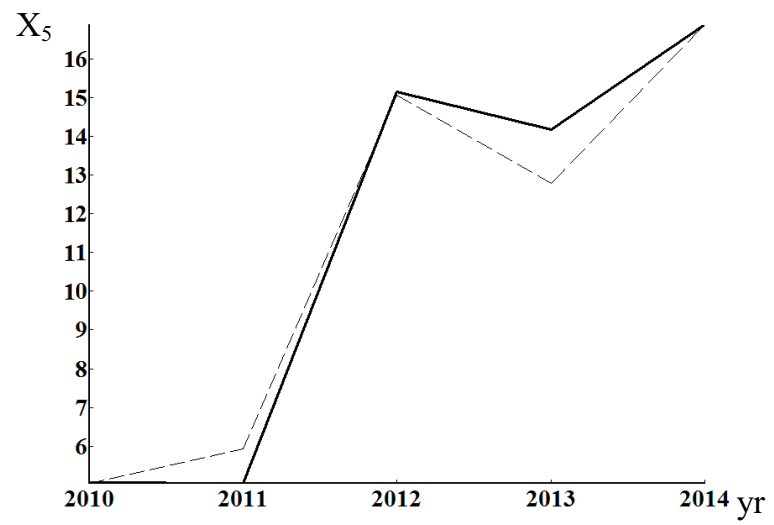

Fig. 2. Working assets.

As can be seen from the graphs, the enterprise operation model that is constructed with the use of the eigenstates method describe the source data rather well.

To match the ongoing by the company's management investment policy with reference complex equation indicator is calculate (6). When calculating the integrated indicator penalty functions are impose on all the factors that have deviations from the reference values more than $10 \%$. The values of the integrated indicator are presented in "Tab. 3".

Table 3. The values of the integrated indicator.

\begin{tabular}{|c|c|c|c|c|c|}
\hline Year & $\mathbf{2 0 1 0}$ & $\mathbf{2 0 1 1}$ & $\mathbf{2 0 1 2}$ & $\mathbf{2 0 1 3}$ & $\mathbf{2 0 1 4}$ \\
\hline $\begin{array}{c}\text { The values of the } \\
\text { integrated } \\
\text { indicator }\end{array}$ & 0.71 & 0.72 & 0.89 & 0.81 & 0.82 \\
\hline
\end{tabular}

As can be seen from Table 3, the company's management is conducting inefficient investment policy (indicator value less than 0.9). Although in recent years, since 2012, investment policy of the enterprise has been revised (the indicator began to rise) and policy approaches to the reference.

Similar rates of investment attractiveness of the investigated companies can be obtained using classical methods, for example, Tobin's method [19-20] or the method of calculating the EVA model system indicators $[5,21,22]$.

According to the method proposed in [4] for evaluation of investment attractiveness analytical Tobin's $\mathrm{Q}$ ratio is calculated. This method relates to the structural and index method of the enterprise investment activity evaluation. Tobin's Q ratio is calculated as the ratio of market capitalization to its net assets at market valuation. If Tobin's $Q$ ratio is less than one, it indicates that the company is undervalued at the market. If the company has an investment activity, the Tobin's $Q$ ratio is growing. If the index is greater than one, it indicates the market interest in the enterprise (market overestimates the enterprise attractiveness).

Tobin's $Q$ ratio describes the efficiency of the net assets to form market value and estimate the enterprise investment attractiveness, but it does not allow to appraise the intensity of investment activity. Calculation of Tobin's Q ratio for the enterprise is presented in "Tab. 4 ".

As it is seen from Table 4, only since 2014, the market value exceeds the company balance sheet assets (Tobin's Q ratio is greater than 1), and therefore it stimulates investors to invest in venture their own funds.

Similar results are obtained by EVA method calculation [5, 21-23]. EVA model system of indicators (Economic Value Added) is economic value added (EVA) which is a venture profit from ordinary activities after tax, reduced by the amount of fees for the entire capital invested in the company [23]. 
Table 4. Tobin's Q ratio calculation.

\begin{tabular}{|c|c|c|c|c|}
\hline figures & $\mathbf{2 0 1 1}$ & $\mathbf{2 0 1 2}$ & $\mathbf{2 0 1 3}$ & $\mathbf{2 0 1 4}$ \\
\hline $\begin{array}{c}\text { net asset } \\
\text { worth, thous. } \\
\text { rub. }\end{array}$ & 1171936 & 11656829 & 10371044 & 12113035 \\
\hline $\begin{array}{c}\text { net income, } \\
\text { thous. rub. }\end{array}$ & 2802860 & 4315767 & 1099401 & 4519763 \\
\hline cap rate & 0,4739653 & 0,61007977 & 0,2319099 & 0,2673245 \\
\hline $\begin{array}{c}\text { Tobin's Q } \\
\text { ratio }\end{array}$ & 0,7227507 & 0,6068634 & 0,4571034 & 1,3958026 \\
\hline
\end{tabular}

EVA index refers to the structural and index method of the enterprise investment activity evaluation. This indicator can be calculated by the following equation:

$$
\begin{aligned}
& E V A=(P-T)-I C \times W A C C=N P-I C \times W A C C= \\
& (N P / I C-W A C C) \times I C==(R O I C-W A C C) \times I C
\end{aligned}
$$

where $P$ - profit from ordinary activities; $T$ - taxation and other compulsory payments; $I C$ - invested capital; $W A C C$ - average weighted price of capital; $N P$ - net income; $R O I C$ - net income return on equity.

The advantage of the EVA system is the use of the economic profit principle based on the capital appreciation analysis to assess the enterprise activity. But, it should be noted that the EVA evaluation system provides indirect investment activity of the enterprise.

The concept of economic value added is based on the use of the principle of economic profit founded on cost accounting of debt and equity attraction. The difference between ROIC and WACC is called profitability spread and gives an indication of the relative efficiency of capital use.

For analyzing enterprise we calculated the EVA indicator for the period 2011-2014 year on the initial data basis. The calculation results can be seen in Table 5 .

Table 5. EVA indicator calculation.

\begin{tabular}{|c|c|c|c|c|}
\hline & $\mathbf{2 0 1 1}$ & $\mathbf{2 0 1 2}$ & $\mathbf{2 0 1 3}$ & $\mathbf{2 0 1 4}$ \\
\hline $\begin{array}{c}\text { net income, } \\
\text { thous. rub. }\end{array}$ & 2802860 & 4315767 & 1099401 & 4519763 \\
\hline $\begin{array}{c}\text { Invested } \\
\text { capital, } \\
\text { thous. rub. }\end{array}$ & -26473 & 11220720 & -765470 & 5445069 \\
\hline $\begin{array}{c}\text { average } \\
\text { weighted } \\
\text { price of } \\
\text { capital }\end{array}$ & 0.14588 & 0.153729 & 0.1523213 & 0.205472 \\
\hline $\begin{array}{c}\text { return on } \\
\text { equity }\end{array}$ & 0.564777 & 0.2786174 & 0.0760470 & 0.2381555 \\
\hline EVA & 0.004005 & $2.0578 \mathrm{E}-08$ & $2.0753 \mathrm{E}-06$ & $1.147 \mathrm{E}-07$ \\
\hline
\end{tabular}

During the reporting periods, EVA index is almost equal to 0 , which means the exploring enterprise traces its investment policy rather inefficiently. In this case, the investor should not expect high returns on investments in the company. However, since the EVA is greater than 0 , it means that the company earns more than its average weighted cost of capital, and therefore, there is value creation. This means an increase in market value of the company over the carrying value of net assets, which encourages owners to further invest in the enterprise.

Comparison of the calculation results of the industrial enterprises investment attractiveness indices obtained with the help of classical methods such as for example, Tobin's method or EVA method showed the adequacy of the mathematical model of industrial enterprise investment appeal which is constructed using the method of eigenstates. However, in contrast with classical methods, the method of constructing an industrial enterprises investment appeal model using the method of eigenstates allows to take into account the hidden relationship between the studied parameters that influence the investment attractiveness.

\section{Conclusions}

Thus, in the article the method of the company investment attractiveness analysis, which is based on the investment attractiveness model formation through an analysis of eigenstates is proposed. In the process of constructing a check of compliance of eigenstates with the enterprise economic stability requirements is implemented. As a numerical evaluation of the investment attractiveness of the company it is proposed to use the enterprises investment attractiveness indicator. It is reasonable to use the value-for-cost principle while constructing the indicator. The research showed that the method of eigenstates can be successfully used for the analysis of investment appeal of industrial enterprise. This method can be used not only by investors, but also by company's management, as results obtained in the model show what indicators reduce the investment attractiveness of the enterprise and, therefore, what set of measures it is necessary to implement to improve the investment attractiveness.

The work was supported by Act 211 Government of the Russian Federation, contract № 02.A03.21.0011.

\section{References}

1. Z. Topaloğlu, International Journal of Finance and Accounting, 1(3), 28-37 (2012)

2. S.C. Guth, M.E. Camargo, António Jorge Fernandes, Maria Elizabeth Pereira Teixeira Rocha, The Scandinavian Journal of Economics, 12, 249-260 (2015)

3. G.P. Podshivalenko, Financial analytics: problems and solutions, 15(39), 7-10 (2010)

4. L.V. Zagorodnova, N.I. Novikov, Bulletin of Kemerovo State University, 2(58), 236-240 (2014)

5. O.J. Tolkachenko, Russian Entrepreneurship, 122, 49-53 (2008)

6. T.V. Fedorovich, The economic analysis: theory and practice, 12(117), 29-35 (2008) 
7. D.V. Doroshin, Directory economist, 8(26), 122128 (2005)

8. W.H. Beaver, M. Correia, M.F. McNichols, Founding and Trends in Accounting, 5, 99-173 (2010)

9. F.M. Rossi, A. Allini, R. Macchioni, J. Ronen, The Scandinavian Journal of Economics, 12, 198210 (2015)

10. G. Stojić, The Scandinavian Journal of Economics, 3, 293-310 (2012)

11. V.V. Mokeev, V.G. Pluzhnikov, Bulletin of South Ural State University of Economics and Management, 41(258), 149-154 (2011)

12. V.V. Mokeev, E.V. Bunova, N.A. Krepak, Bulletin of South Ural State University. A series: Computer technology, management, electronics, 4, 73-81 (2014)

13. S. Buslaeva, The problems of the modern economy, 3, 6-24 (2014)

14. I.Y. Deaf, Management Consulting, 3, 185-195 (2011)
15. V.V. Mokeev, C.L. Solomakho, Investment management, 4, 26-33 (2011)

16. V.V. Mokeev, Economics and Mathematical Methods, 4, 82-90 (2010)

17. V.V. Mokeev, D.A. Vorobyev, Bulletin of South Ural State University. Series: Computer technology, management, electronics, 2, 31-40 (2014)

18. V.V. Mokeev, Scientific and technical information. Information processes and systems, 9, 3-14 (2014)

19. I.G. Ershova, I.V. Androsov, Vector Science TSU, 4(30), 108-112 (2014)

20. S.V. Baguzin, Strategic management, 4(28), 242256 (2014)

21. V. Burešová, L. Dvořáková, Wseas Transactions on Business and Economics, 11, 525-536 (2014)

22. I.V. Ilin, A.B. Anisiforov, Wseas Transactions on Business and Economics, 11, 757-764 (2014)

23. O.N. Shcherbakova, Financial Management, 3, 27-35 (2003) 